\title{
Vaccination Coverage and the Risk of Hepatitis $B$ Virus Infection amongst Medical and Paramedical Students Practicing at the Bamenda Regional Hospital in Cameroon Sub-Saharan Africa
}

\author{
Milca A. Asanghanwa ${ }^{1 *}$, Menji B. Nyuykighan1, Odelia Kwende-Tanjong², Esther Agbor ${ }^{1}$ \\ ${ }^{1}$ Department of Medical Laboratory Science, Faculty of Health Sciences, University of Bamenda, Bambili, Cameroon \\ ${ }^{2}$ Department of Nursing, Faculty of Health Sciences, University of Bamenda, Bambili, Cameroon \\ Email: *masangha@yahoo.com
}

How to cite this paper: Asanghanwa, M.A., Nyuykighan, M.B., Kwende-Tanjong, O. and Agbor, E. (2021) Vaccination Coverage and the Risk of Hepatitis B Virus Infection amongst Medical and Paramedical Students Practicing at the Bamenda Regional Hospital in Cameroon Sub-Saharan Africa. International Journal of Clinical Medicine, 12, 211-223.

https://doi.org/10.4236/ijcm.2021.125020

Received: April 20, 2021

Accepted: May 24, 2021

Published: May 27, 2021

Copyright $\odot 2021$ by author(s) and Scientific Research Publishing Inc. This work is licensed under the Creative Commons Attribution International License (CC BY 4.0).

http://creativecommons.org/licenses/by/4.0/ (c) (i) Open Access

\begin{abstract}
Introduction: The endemic nature of hepatitis B virus (HBV) in Sub-Saharan Africa is a significant public health problem that places health care providers (medical students inclusive) at increased risk of occupational exposure. However, vaccination against HBV is not systematic among medical students in Cameroon. Thus, we sought to evaluate awareness and HBV vaccine coverage amongst medical students in Cameroon. Aim: The present study was aimed at determining the proportion of Medical and Paramedical students on internship at the Bamenda Regional Hospital (BRH) who are vaccinated and immune to hepatitis B virus (HBV). Methods: This was a hospital-based cross sectional study carried out at the BRH in Cameroon. Questionnaires were administered to 120 participants who signed an informed consent form and venous blood samples collected in dry tubes for the HBV-5 PANEL test. Data were collected within a period of two weeks. HBV vaccine status was defined as complete ( 3 doses), partial (1 or 2 doses), and unvaccinated. Results: Of 120 participants ( 87 females and 33 males), 56 (46.7\%) were vaccinated at least once against HBV; 15 (12.5\%) were partially vaccinated and 41 (34.2\%) completely vaccinated. Out of the 56 vaccinated individuals, only 13 (23.2\%) were confirmed immunized against HBV by testing positive for hepatitis B surface antibodies. Only 3 (5.4\%) students had done post-vaccination serologic test to confirm their immunized status. There was high exposure to potentially infected body fluids like blood (97.5\%) and urine (87.5\%). There was equally poor practice of adequate preventive measures like regular hand
\end{abstract}


washing and the proper use of personal protective equipment. A prevalence of $3.1 \%$ of HBV amongst the unvaccinated group was recorded. Conclusion: Only 1 in 3 medical students had completed the HBV vaccination series and only $26.8 \%$ of this cohort was confirmed immunized against HBV. This highlights the need for improved health policies aimed at increasing access and coverage of HBV immunization in high risk groups such as health workers.

\section{Keywords}

Hepatitis B Virus, Hepatitis B Surface Antibodies, Immunization, Medical and Paramedical Students

\section{Introduction}

Hepatitis B virus (HBV) infection is a global public health problem affecting millions of people every year and causing disability and death [1]. Globally, it is estimated that approximately 257 million people are infected, particularly in low-income and middle-income countries [2] [3]. About 1 million people die each year ( 2.7\% of all deaths) from causes related to viral hepatitis, mostly liver disease including liver cancer and cirrhosis [1] [4]. Hence, it is considered the tenth leading cause of death worldwide [5]. Despite the increasing seroprevalence, there is no routine screening of high risk groups in most countries because of lack of public awareness, inadequate funding for health care settings, and the expensive nature of the test [6]. Though the lifetime risk of contracting HBV in the general population is $4.8 \%$, this can be reduced significantly through vaccination. For example, infant vaccination reduces this value by $68 \%$, while adolescent vaccination reduces it by 45\% [7]. Health care personnel (including Medical and Paramedical students) are at an unavoidable higher risk of contracting blood borne pathogens like HBV due to their interaction with patients [8]. Fortunately, Hepatitis B virus vaccine has been present for over three decades to prevent this well-known occupational disease [5]. Immunization is achieved in $95 \%$ of the population following the administration of three doses of $\mathrm{HBV}$ vaccine at zero, first and the sixth month respectively. To ascertain the immunity, antibodies against HBV surface antigens (anti-HBs) are measured 6 to 8 weeks following the administration of the third dose of the vaccine. Anti-HBs greater than 100 $\mathrm{IU} / \mathrm{mL}$ imply good response to the vaccine while values between 10 and 100 $\mathrm{IU} / \mathrm{mL}$ will require immediate booster dose to improve response and antibodies measured again in 6 to 8 weeks' time. Furthermore, all those vaccinated need a booster dose of the vaccine after 10 years since the antibody titer declines with time [9]. The vaccine is produced following the purification of HBsAg obtained from the plasma of persons with chronic HBV infection [10] [11] [12]. This vaccine is meant to prevent $\mathrm{HBV}$ infection and its associated liver complications [10]. To achieve this, the vaccine must trigger an immune response which would produce anti-HBs at a concentration of $>10 \mathrm{IU} / \mathrm{mL}$ at least 1 month and at most 
2 months after the $3^{\text {rd }}$ dose [13] [14]. About 5\% - 15\% of vaccines may not develop the expected immune response following the complete dose administration of the vaccine [15]. Usually, about $30 \%-50 \%$ of people who do not respond to a primary 3-dose vaccine series with anti-HBs concentrations of $>10 \mathrm{IU} / \mathrm{mL}$, may respond to an additional vaccine dose or to a 3-dose revaccination series [15] [16]. Vaccination coverage of healthcare personnel (HCP) against this virus remains low especially in some developing countries. For example; in a research to determine the prevalence and vaccination coverage against $\mathrm{HBV}$ among $\mathrm{HCP}$ in Cameroon of a seroprevalence survey, only 199 (11.4\%) of the 1747 participants were fully vaccinated [17]. In this study, we aimed at investigating vaccination coverage and the assessment of risk factors for HBV amongst medical and paramedical students on internship at the Bamenda Regional Hospital in Cameroon.

\section{Methods}

This was a hospital-based cross sectional study that made use of a self-administered questionnaire and the Aria HBV-5 RAPID TEST for hepatitis B surface antigen (HBsAg), antibodies against hepatitis B surface antigen (anti-HBs), hepatitis B viral protein ( $\mathrm{HBeAg})$, antibodies against hepatitis B viral protein (anti-HBe) and antibodies against hepatitis B core antigen (anti-HBc). The study was carried out at the Bamenda Regional Hospital (BRH) within the month of June 2020. The study population consisted of Medical and Paramedical students practicing at the BRH. Blood samples for the acquisition of biological data were collected from participants who consented and completed a questionnaire designed to obtain demographic data (age, sex, marital status) and information regarding knowledge of HBsAg status, whether or not they have received the HBV vaccine, the number of doses, the reason for non-vaccination for those who had not been vaccinated and their knowledge about the possible risk factors or exposure to HBV at their area of work. The questionnaire was made in English, pre-tested for clarity in a pilot study and adjusted accordingly. The sample size was calculated using the Cochran formula $n=\frac{z^{2} p(1-p)}{d^{2}}$; where $n=$ minimum required sample size, $z=$ confidence level at $95 \%$ (standard value of 1.96), $p=$ estimated prevalence of the infection among the population under investigation and $\mathrm{d}=$ type 1 error set at $5 \%$. According to a previous study involving medical and paramedical staff of the Central Hospital in Yaounde-Cameroon, the prevalence of hepatitis B was $6.6 \%$ [18]. Hence,

$n=\frac{1.96^{2} \times(0.066) \times(1-0.066)}{(0.05)^{2}}=98.5 \cong 100$. For this study, we had a total of 120 participants.

\section{Ethical Considerations}

Ethical Clearance according to the Declaration of Helsinki was sought from the 
Institutional Review Board of the Faculty of Health Sciences, University of Bamenda. Authorization was also gotten from the Director of the Bamenda Regional Hospital. Written informed consents were obtained from participants following careful explanation of the study protocol.

\section{Statistical Analysis}

Results were recorded into a log book; filled questionnaires coded and all data obtained keyed into Microsoft Office Excel and imported to Statistical Software Package for Social Science (SPSS) version 22.0 for statistical analysis. Categorical variables were summarized using proportions and displayed on Tables and Charts.

\section{Results}

This study involved 120 participants; 87 (72.5\%) females and 33 (27.5\%) males. Majority of the participants 112 (93\%) were aged 20 - 30 years; 99 (82.5\%) were single and $21(17.5 \%)$ married. With respect to professional status, the study involved 45 (37.5\%) Nursing/Midwifery students, 40 (33.3\%) Medical Laboratory Science students and 35 (29.2\%) Medical students. These students were either working in General Medicine, the Medical Diagnostic Laboratory, the Surgical Department of the hospital or in Obstetrics and Gynaecology units (Table 1). The proportion of medical and paramedical students completely vaccinated (received all three doses of the vaccine) against HBV was $34.2 \%$ (41 participants);

Table 1. Demographic characteristics of the study population.

\begin{tabular}{|c|c|c|c|}
\hline Characteristic & Category & Frequency (N) & Percentage (\%) \\
\hline \multirow{2}{*}{ SEX } & Male & 33 & 27.5 \\
\hline & Female & 87 & 72.5 \\
\hline \multirow{4}{*}{ AGE RANGE/years } & $15-19$ & 7 & 5.8 \\
\hline & $21-24$ & 93 & 77.5 \\
\hline & $25-29$ & 19 & 15.8 \\
\hline & $\geq 30$ & 1 & 0.8 \\
\hline \multirow{3}{*}{ MARITAL STATUS } & Married & 21 & 17.5 \\
\hline & Single & 99 & 82.5 \\
\hline & Divorced & 0 & 0.0 \\
\hline \multirow{3}{*}{ PROFESSION } & Medicine & 35 & 29.2 \\
\hline & Nursing/Midwifery & 45 & 37.5 \\
\hline & Medical lab scientist & 40 & 33.3 \\
\hline \multirow{4}{*}{ DEPARTMENT } & General Medicine & 46 & 38.3 \\
\hline & Obstetrics and gynecology & 32 & 26.7 \\
\hline & Surgery & 2 & 1.7 \\
\hline & Laboratory & 40 & 33.3 \\
\hline Total & Overall & 120 & 100.0 \\
\hline
\end{tabular}


$15(12.5 \%)$ were partially vaccinated (received 1 or 2 doses of the vaccine) against $\mathrm{HBV}$ and 64 (53.3\%) participants had not received any dose of the vaccine (unvaccinated) (Figure 1). Reasons provided by the non-vaccinated group included; lack of money (73\%), lack of time (8\%), not aware of the existence of the HBV vaccine (8\%), not aware of where to get the vaccine $(6 \%)$, scared of side effects (3\%) and rather scared of being infected by HBV through the administration of a vaccine $(2 \%)$.

Out of the 56 vaccinated participants, only 13 (23.2\%) were actually immune to $\mathrm{HBV}$ by testing positive for anti-HBs. A greater proportion of the vaccinated participants $43(76.8 \%)$ were negative for anti-HBs and not immunized against HBV (Figure 2).

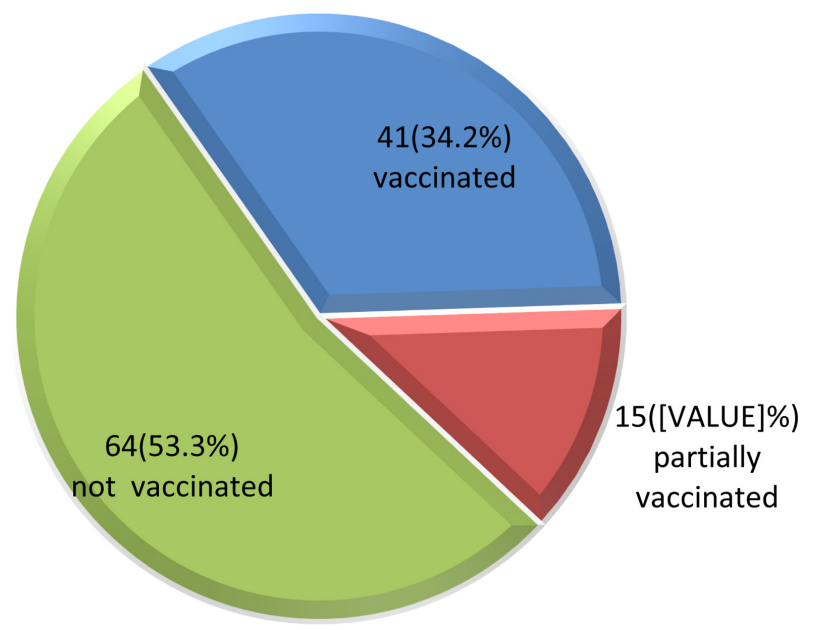

Figure 1. Percentage of vaccinated medical and paramedical students.

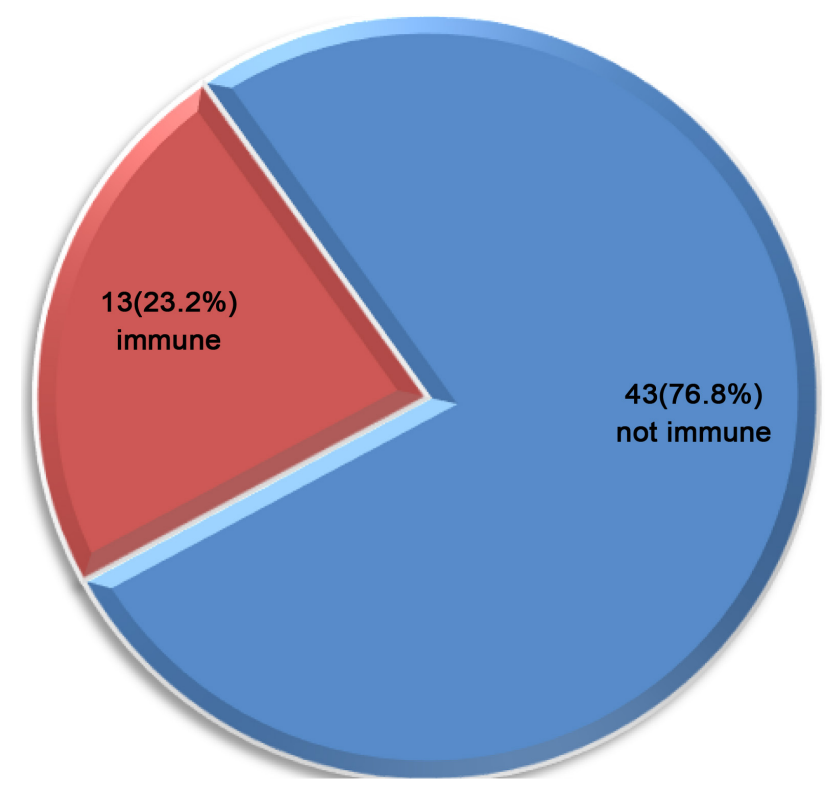

Figure 2. Proportion of immunized and non-immunized vaccinated participants. 
The main body fluids study participants were exposed to included blood (97.5\% of participants), vaginal discharge (88\%), urine $(87.5 \%)$ and sweat (86.3\%). Other body fluids exposed to included CSF, sputum and saliva: $39.2 \%$, $28.3 \%$ and $26.7 \%$ respectively (Figure 3 ). The highest exposure activity was the use of syringes for injection (55.9\%), followed by venous blood collection (33.9\%) (Table 2). Regular hand washing was practiced by 67 (55.8\%) students while $47(39.3 \%)$ washed their hands at times and $6(5.0 \%)$ students rarely engaged in this practice (Figure 4). Regarding the use of Personal Protective Equipment (PPE), 55 (45.8\%) students admitted to the regular use of PPE before any contacts with body fluids whereas the remaining 65 (54.2\%) personnel did not use PPE regularly (Figure 5). All participants (100\%) were aware they are exposed to HBV by the nature of their job.

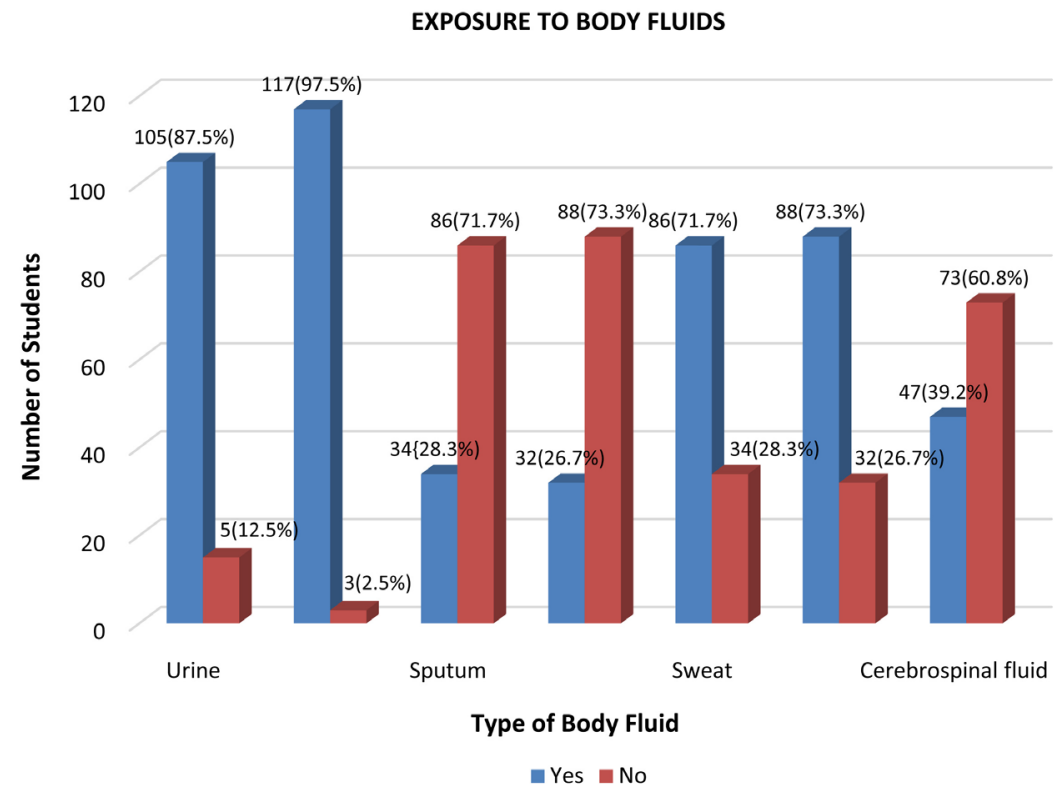

Figure 3. Proportion of exposure to different body fluids amongst medical and paramedical students.

\section{PRACTICE OF HAND WASHING}

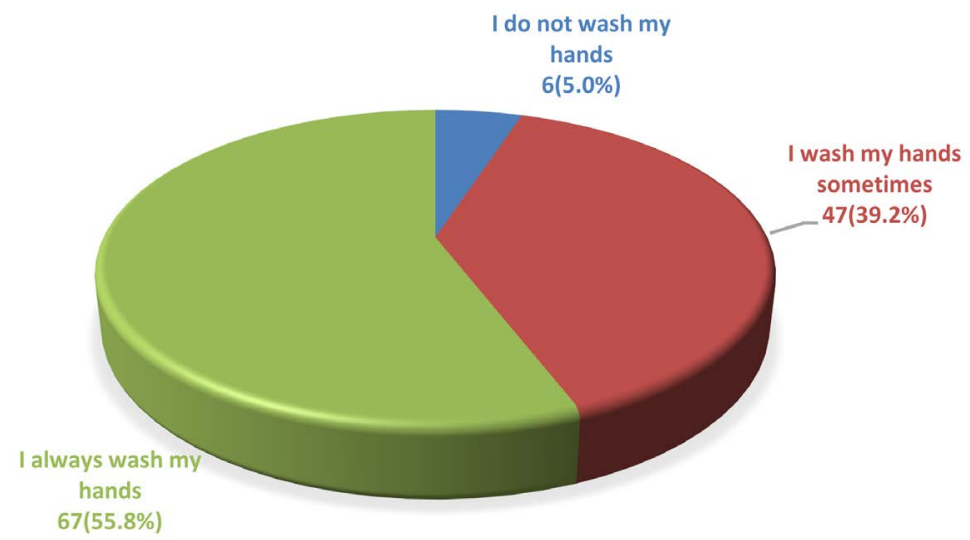

Figure 4. Practice of hand washing by medical and paramedical students. 


\section{USE OF PERSONAL PROTECTIVE EQUIPEMENTS (PPE) AT WORK}

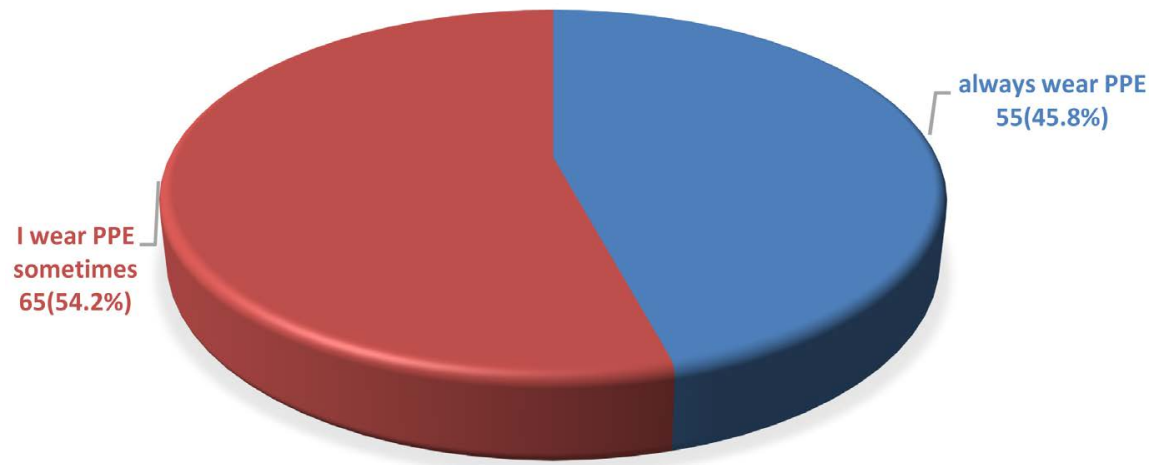

Figure 5. The use of PPE amongst medical and paramedical students.

Table 2. Number and proportion of students involved in exposure activity.

\begin{tabular}{ccc}
\hline & Exposure activities & \\
\hline Variable & Frequency & Percentage \\
\hline Surgery & 6 & $10.2 \%$ \\
Preparing or giving injection & 33 & $55.9 \%$ \\
Venous blood collection & 20 & $33.9 \%$ \\
Total & 59 & $100 \%$ \\
\hline
\end{tabular}

\section{Discussion}

This study was to determine the vaccination coverage of medical and paramedical students practicing at the Bamenda Regional Hospital in Cameroon Sub Saharan Africa. We noted that less than 50 per cent of these students had received the $\mathrm{HBV}$ vaccine and only 34 per cent of the vaccinated group had actually taken all three required doses of the vaccine. This is similar to studies carried out in other developing countries like Nigeria with a proportion of those who had received all three doses of the vaccine to be 34.8 per cent [19], but higher compared to a previous study in Cameroon with just 16.8 per cent of the participants who had received all three doses of the vaccine [20]. However, in a study involving health care workers; doctors and nurses in the United States of America (USA), a high proportion (81\%) of the participants had received at least three doses of the vaccine [21]. The difference in vaccination coverage from one county to another could be explained by the fact that some governments have strict health care personnel vaccination policies whereas others do not [22] [23].

In this study, of the 56 students who had been vaccinated against HBV, only 13 (23.2\%) participants were positive for antibodies against the hepatitis B surface antigen confirming immunization against the virus. The results were in line with a study in Nigeria by Olumuyiwa Odusanya et al. [24] where these antibodies were detected in 17.9 per cent of the vaccinated participants. We therefore emphasize on the fact that although an individual may have received the vaccine, there is need to verify for immunization post the vaccination process. 
Six to eight weeks after completion of vaccination, it is necessary to measure anti-HBs in order to confirm immunization or the need for re-vaccination/booster vaccine; however, only 3 (5.4\%) of the fully vaccinated participants in this study had undergone antibody testing to confirm their immunization status. We propose the need for sensitization and strict vaccination policies to ensure that those vaccinated especially health workers at high risk, are actually protected against this infection.

Two (3.1\%) of the 64 participants who had not been vaccinated against HBV tested positive for $\mathrm{HBsAg}$ following a rapid screening procedure. It was noted from this study that almost all participants (97.5\%) are exposed to blood either during procedures like setting up of intravenous lines, medical laboratory diagnostic activities or during major or minor surgical procedures. Given the fact that HBV is found in high concentrations in blood of infected individuals, the high prevalence of the virus in Cameroon but a low vaccination/immunization coverage, medical workers including medical or paramedical students on internship are at high risk of contracting the infection, necessitating health measures or government policies to enhance prevention.

We realized in current study that despite the high rate of exposure to potentially infectious biological fluids by participants, only $55.8 \%$ of the medical and paramedical students do disinfect their hands regularly by washing them during or after their routine activities involving getting in contact with these body fluids (Figure 4). Thus, an increase in their chances of contracting or transmitting highly infectious pathogens like HBV, Human Immunodeficiency Virus (HIV) and Hepatitis $\mathrm{C}$ virus (HCV), and this is exacerbated by the irregular use of personal protective equipment (PPE) by more than 50 per cent of the study participants (Figure 5). High exposure to hepatitis B in this study is comparable to that of Attaullah et al. [23] with occupational exposure through drawing of blood, recapping of syringes, disposal of used needles, insertion of drip, trash collections, surgical procedures, collision with sharp objects, fluid splashes, and cleaning of instruments.

Considering the unvaccinated group, up to 73 per cent of participants complained of lack of money as reason for not having taken the vaccine. In our setting, these vaccines are usually free during vaccination campaigns but are actually paid for off such periods and at a cost that might not permit non-salary earners like students to obtain. We therefore suggest that authorities of health institutions should consider sponsoring or subsidizing the HBV vaccine to facilitate and ensure its acquisition by students prior to their final year of internship in a hospital environment.

\section{Conclusion}

HBV infection is an important occupational hazard among health care personnel potentially preventable by vaccination and compliance to bio-safety measures at work. From this study, immunity against HBV due to vaccination amongst 
medical and paramedical students working at the BRH is low. Only $13(23.21 \%)$ of the 56 vaccinated students were actually immune to HBV by testing positive for anti-HBs. The prevalence of HBV following a screening exercise for participants in the unvaccinated group was $3.1 \%$. Exposure is mainly by injuries due to the use of syringes for injection or blood sampling, and surgical procedures with poor practice of biosafety measures. We recommend strict government policies regarding vaccination against $\mathrm{HBV}$, and the organization of regular seminars or educational programs by hospital authorities especially in developing countries, to ensure that safety measures are reliably followed by health workers to curb the spread of HBV and other life threatening infectious diseases.

\section{Limitation of the Study}

The Aria HBV-5 Rapid Test is limited to the qualitative detection of HBsAg, anti-HBs, $\mathrm{HBeAg}$, anti-HBe and anti-HBc in human serum or plasma. Data regarding vaccination status was obtained through self-provided information which could be subjected to recall bias.

\section{Conflicts of Interest}

The authors declare no conflict of interest.

\section{References}

[1] World Health Organization (2012) Prévention et lutte contre l'hépatite virale: Cadre pour l'action mondiale. World Health Organization, Geneva. http://www.who.int/csr/diesease/hepatitis/GHP-Framework-Fr.pdf

[2] World Health Organization (2017) Hepatiti B: Factsheet. http://www.who.int/mediacentre/factsheets/fs204/en/index.html

[3] World Health Organization (2015) Guidelines for the Prevention, Care and Treatment of Persons with Chronic Hepatitis B Infection. http://apps.who.int/iris/bitstream/10665/154590/1/9789241549059 eng.pdf

[4] World Health Organization (2009) Executive Board: Viral Hepatitis. http://apps.who.int/gb/ebwha/pdf files/EB126/B126 15-en.pdf

[5] Lavanchy, D. (2004) Hepatitis B Virus Epidemiology, Disease Burden, Treatment, Arid Current and Emerging Prevention and Control Measures. Journal of Viral Hepatitis, 11, 97-107. https://doi.org/10.1046/j.1365-2893.2003.00487.x

[6] Memon, M.S., Ansari, S., Nizamani, R., Khatri, N.N., Mirza, M.M. and Jafri, W. (2007) Hepatitis B Vaccination Status in Health Care Workers of Two University Hospitals. Journal of Liquate University Medical and Health Science, 6, 48-51. https://doi.org/10.22442/jlumhs.07620115

[7] Margolis, H.S., Coleman, P.J., Brown, R.E., Mast, E.E., Sheingold, S.H. and Arevalo, J.A. (1995) Prevention of Hepatitis B VIRUS Transmission by Immunization. An Economic Analysis of Current Recommendations. JAMA, 274, 1201-1208. https://doi.org/10.1001/jama.1995.03530150025029

[8] Sharma, R., Rasania, S.K., Verma, A. and Singh, S. (2010) Study of Prevalence and Response to Needle Stick Injuries among Health Care Workers in a Tertiary Care Hospital in Delhi, India. Indian Journal of Community Medicine, 35, 74-77. https://doi.org/10.4103/0970-0218.62565 
[9] Sukriti, Pati, N.T., Sethi, A., Agrawal, K., Agrawal, K., Kumar, G.T., Kumar, M., Kaanan, A.T. and Sarin, S.K. (2008) Low Levels of Awareness, Vaccine Coverage, and the Need for Boosters among Health Care Workers in Tertiary Care Hospitals in India. Journal of Gastroenterology and Hepatology, 23, 1710-1715. https://doi.org/10.1111/j.1440-1746.2008.05483.x

[10] Mast, E.E., Weinbaum, C.M., Fiore, A.E., Alter, M.J., Bell, B.P., Finelli, L., et al. (2006) A Comprehensive Immunization Strategy to Eliminate Transmission of Hepatitis B Virus Infection in the United States. Morbidity and Mortality Weekly Report, 55, 1-33.

[11] Stephenne, J. (1990) Development and Production Aspects of a Recombinant Yeast-Derived Hepatitis B Vaccine. Vaccine, 8, S69-S73, Discussion S79-S80. http://www.ncbi.nlm.nih.gov/pubmed/2139287PMID2139287 https://doi.org/10.1016/0264-410X(90)90221-7

[12] Merck (2010) Hepatitis B Vaccine. http://www.rxlist.com/recombivax-drug.htm

[13] Centers for Disease Control and Prevention (2017) Ask the Experts about Hepatitis B Vaccines CDC Experts Answer Q\&As. In: Immunization Action Coalition. http://www.immunize.org/askexperts/experts hepb.asp

[14] Roukens, A.H. and Visser, L.G. (2011) Hepatitis B Vaccination Strategy in Vaccine Low and Non-Responders: A Matter of Quantity of Quality? Human Vaccines, 7, 654-657. https://doi.org/10.4161/hv.7.6.14986

[15] Schillie, S., Murphy, T.V., Sawyer, M., Ly, K., Hughes, E., Jiles, R., et al. (2013) CDC Guidance for Evaluating Healthcare Personnel for Hepatitis B Virus Protection and for Administering Postexposure Management. Morbidity and Mortality Weekly Report, 62, 1-19.

[16] Kim, M.-J., Nafziger, A.N., Harro, C.D., Keyserling, H.L., Ramsey, K.M., Drusano, G.L., et al. (2003) Revaccination of Healthy Nonresponders with Hepatitis B Vaccine and Prediction of Seroprotection Response. Vaccine, 21, 1174-1179.

http://www.ncbi.nlm.nih.gov/pubmed/12559795

https://doi.org/10.1016/S0264-410X(02)00626-6

[17] Biloungo, C., Eteki, L., Siedner, M., Mbaye, R., Chen, J., Ntone, R., et al. (2018) Prevalence and Vaccination Coverage of Hepatitis B among Healthcare Workers in Cameroon: A National Seroprevalence Survey. Journal of Viral Hepatitis, 25, 1582-1587. https://doi.org/10.1111/jvh.12974

[18] Noah, D.N., Ngaba, G.P., Bagnaka, S.F., Assi, C., Ngantchet, E. and Njoya, O. (2013) Evaluation of Vaccination Status against Hepatitis B and HBsAg Carriage among Medical and Paramedical Staff of the Yaoundé Central Hospital, Cameroon. Pan African Medical Journal, 16, Article No. 111.

https://doi.org/10.11604/pamj.2013.16.111.2760

[19] Paul, N. and Peterside, O. (2015) Hepatitis B Vaccination Rate among Medical Students at the University of Port Harcourt Teaching Hospital (Upth). World Journal of Vaccines, 5, 1-7. https://doi.org/10.4236/wjv.2015.51001

[20] Aroke, D., Kadia, B.M., Anutebeh, E.N., Belanquale, C.A., Misori, G.M., Awa, A., et al. (2018) Awareness and Vaccine Coverage of Hepatitis B among Cameroonian Medical Students. BioMed Research International, 2018, Article ID: 3673289, 6 p. https://doi.org/10.1155/2018/3673289

[21] Simard, E., Miller, J., George, P., Wasley, A., Alter, M., Bell, B., et al. (2007) Hepatitis B Vaccination Coverage Levels among Healthcare Workers in the United States 2002-2003. Infection Control \& Hospital Epidemiology, 28, 783-790. 
https://doi.org/10.1086/518730

[22] Singhal, V., Bora, D. and Singh, S. (2009). Hepatitis B in Health Care Workers: Indian Scenario. Journal of Laboratory Physicians, 1, 41-48.

[23] Attaullah, S., Khan, S., Naseemullah, Ayaz, S., Khan, S.N., Ali, I., Hoti, N. and Sira, S. (2011) Prevalence of HBV and HBV Vaccination Coverage in Health Care Workers of Tertiary Hospitals of Peshawar, Pakistan. BMC Virology Journal, 8, Article No. 275. https://doi.org/10.1186/1743-422X-8-275

[24] Olumuyiwa, O., Meurice, F.P. and Hoet, B. (2007) Nigerian Medical Students Are at Risk for Hepatitis B Infection. Transactions of the Royal Society of Tropical Medicine and Hygiene, 101, 465-468. https://doi.org/10.1016/j.trstmh.2006.08.001 


\section{Appendix}

\section{Questionnaire}

\section{Section One: Demographic Data}

1) age in years: $15-19$ [ ], $21-24$ [ ], $25-29$ [ ], $\geq 30$ [ ]

2) Gender: Male [ ], Female [ ]

3) Marital status: Married [ ], Single [ ], Divorced [ ]

4) In which ward/department of the hospital do you work?

General Medicine [ ], Obstetrics and gynecology [ ], surgery [ ], Laboratory [ ], others [ ]

5) Which of these best applies to you regarding your profession

Medicine [ ], Nursing/Midwifery [ ], Medical laboratory science [ ]

\section{Section Two: Knowledge (Awareness of Risk) and Vaccination Status}

6) Are you aware you are at risk of contracting Hepatitis B due to your profession? YES [ ], NO [ ], I don't know [ ]

7) Have you ever been tested for hepatitis B? YES [ ], NO [ ]

8) Do you know your hepatitis B status? YES [ ], NO [ ]

9) Have you ever been treated for hepatitis B? YES [ ], NO [ ]

10) Have you heard about the hepatitis B vaccine? YES [ ], NO [ ]

11) Have you been vaccinated against hepatitis B virus? YES [ ], NO [ ]. if NO please move to question 20.

12) How many doses of the vaccine did you receive? One Dose [ ], Two Doses [ ], Three Doses [ ]

13) How long has it been since you took the vaccine? Few months [ ], $1-5$ years [ ], 6 - 10 years [ ], >10 years [ ]

14) Did you ever do any test to confirm immunization against the virus? YES [ ], NO [ ]

15) If YES, what were you told?

I was told the vaccination process was successful [ ]

I was told that I need to take another dose of the vaccine [ ]

None of the above [ ]

16) If you were told to take another dose of the vaccine, did you? NO [ ], YES [ ]

17) If YES, when were you asked to come back for confirmation?

Six weeks [ ], eight weeks [ ] not mentioned [ ]

18) Have you ever taken a booster dose of the vaccine? YES [ ], NO [ ]

19) What was your source of the vaccine? Regional Delegation [ ], Hospital [ ], Pharmacy [ ]

20) I have not been vaccinated against hepatitis $B$ virus because:

I do not think the vaccine is effective [ ],

I do not know where to get the vaccine [ ],

I have never heard about the vaccine [ ],

I do not have enough time to go and get the vaccine [ ],

I do not have enough money to buy the vaccine [ ],

I am afraid of the side effects of the vaccine [ ]

I am not at risk of getting hepatitis B virus [ ]

I think the vaccine will infect me with hepatitis B virus [ ]

I have colleagues who are vaccinated but are not immune, so I can't waste my time [ ]

If none of the above, please specify

\section{SECTION THREE: RISK FACTORS AT WORK}

21) Which of the following do you come in contact with? 
Urine [ ], Blood [ ], Sputum [ ], Saliva [ ], Sweat [ ], Vaginal Fluid [ ], Cerebrospinal fluid [ ], none [ ]

22) Before handling the above fluid,

I do not wear gloves [ ], I wear gloves sometimes [ ], I must wear gloves [ ]

23) After contact with patient/body fluid,

I do not wash my hands [ ], I wash my hands sometimes [ ], I always wash my hands [ ]

24) Can you say with all honesty that you always wear your PPE when on duty? YES [ ] NO [ ]

25) I have had accidental exposure to hepatitis $B$ when performing the following via a needle prick;

Surgery [ ], preparing or giving injection [ ], venous blood collection [ ]

26) Do you think the hospital is properly disinfected, YES [ ], NO [ ] 